Mava Y

Chinda JY

Alhaji MA

Nggada HA

\section{Childhood ovarian juvenile granulosa cell tumour: a case report and review of literature}

DOI:http://dx.doi.org/10.4314/njp.v39i4,11.

Accepted: 12th May 2012

Mava Y ( $\square)$

Alhaji MA

Department of Paediatrics

Chinda JY

Department of Paediatrics singun

Nggada HA

Department of Histopathology,

University of Maiduguri Teaching

Hospital, Maiduguri Nigeria.

Email: yakubumara@gmail.com

Tel: +2348036301748

\begin{abstract}
Juvenile granulosa cell tumour (JGCT) is very uncommon gynecological malignancy that occurs more commonly in under five years old of age. We describe a case of JGCT in a 4-years old girl. The malignancy is assigned to International Federation of Gynecology and Obstetric staging system (FIGO stage I). Treated with complete excision only, the patient showed no evidence of relapse one year after surgery.
\end{abstract}

Findings in this case are discussed and histological examination confirmed the diagnosis. The natural history of JGCT, epidemiology, histology, treatment and prognosis are reviewed along with the case presentation.

Key words: Childhood, Juvenile Granulosa Cell, Tumour, Ovary

\section{Introduction}

Ovarian JGCT is extremely rare sex cord-stromal tumour. ${ }^{1}$ It comprises only $5 \%$ of ovarian tumours of childhood or adolescence. ${ }^{2}$ Mohammed et al ${ }^{3}$ from Zaria Northern Nigeria reported only two cases of JGCT among children 15 years and bellow in a 25 years review of ovarian malignancies in childhood. Typically they present as sexual precocity in prepubertal girls due to excessive estrogen production. In some rare cases androgens may be produced. ${ }^{2}$ JGCT is different from adult granulosa cell tumour (AGCT) that is seen in older females with respect to clinical and pathological features as well as biological behaviours. ${ }^{4}$ Common symptoms include abdominal swelling, abnormal uterine bleeding, appearance of acne, breast enlargement and occasional facial hair appearance. There are no known risk factors for this tumour but recently, associations with changes in certain chromosomes were suspected. ${ }^{5}$ Such changes include Gas-activating mutations in hot spots position 201. Specifically, mutations R201C and R201H were exclusively localized in granulosa cell tumours. ${ }^{6}$

Juvenile granulosa cell tumour a subtype of ovarian stromal cell tumours, has a favourable prognosis if diagnosed at early stage. Recurrences are uncommon and typically occur within the first year. ${ }^{7}$ The incidence of this group of tumour is same throughout the world. ${ }^{3,8}$

A more serious estrogen effects can occur in various end organs such as endometrial hyperplasia, endometrial adenocarcinomas and increased risk of breast cancers. ${ }^{8}$ Granulosa cell tumours can occur in the juvenile and adult male testes, though very rare. ${ }^{8}$ Majority of JGCT present as localized disease confined to the ovary, ${ }^{9}$ and usually behave in a benign manner despite having histopathological features of malignancy. ${ }^{4,9}$ Conversely, advanced JGCT and poorly differentiated sertolic cell tumours are considered prognostically poor. ${ }^{9}$ Histopathologically, ovarian follicles are irregular in size and shape, leutenization occurs and the nuclei are immature, atypical and have a high mitotic rate. Exner bodies are classic features. These are grooved, pale and round nuclei. ${ }^{10}$ A positive immunohistochemical stain for inhibin, an ovarian glycoprotein is a key diagnostic feature. ${ }^{10}$

Various modalities of treatment have been used ranging from surgical removal of the tumour to chemotherapy, radiotherapy and other treatments. ${ }^{5,10}$ In adolescent girls and adult females, fertility sparing surgery can be done. Some have used platinum agent as standard treatment, either combined with Vinblastine and Bleomycine or Adriamycine and Cyclophosphomide. ${ }^{4,10}$ Other authors now recommend the use of Bleomycin, Eptoposide and Platinum. Some studies suggested that patients aged 19 years and below should have surgery and close monitoring for tumour recurrence only. ${ }^{4,10}$ Others have used stem cell transplantation. ${ }^{5}$ Newer agents that block angiogenesis are being studied; two are being tried currently; sunitinib and bevacizumab. ${ }^{5}$ Hormone based treatments like paclitaxel and taxane in combination with platinum are also being advocated. ${ }^{10}$ The use of radiotherapy has not been shown to confer any survival benefit to JGCT at any stage. This case report is reported in a four year old girl to highlight clinical presentation, histologic characteristics of this rare tumor to remind 
clinicians the necessity to achieve correct diagnosis and proper selection of treatment protocol.

\section{Case report}

A four year old girl presented with a two month history of progressive abdominal swelling, one month history of fever and one week history of cough. There was associated progressive weight loss, no history suggestive of tuberculosis. Painless breast enlargement preceded the abdominal swelling; there was an associated abdominal pains but no history of vaginal bleeding. Examination revealed bilateral breast enlargement (Fig 1a) and galactorrhoea in either breasts but no adrenarche or significant peripheral lymphadenopathy.

Fig 1a: Bilateral breast enlargement with galactorrhoea in a four year old girl with JGCT

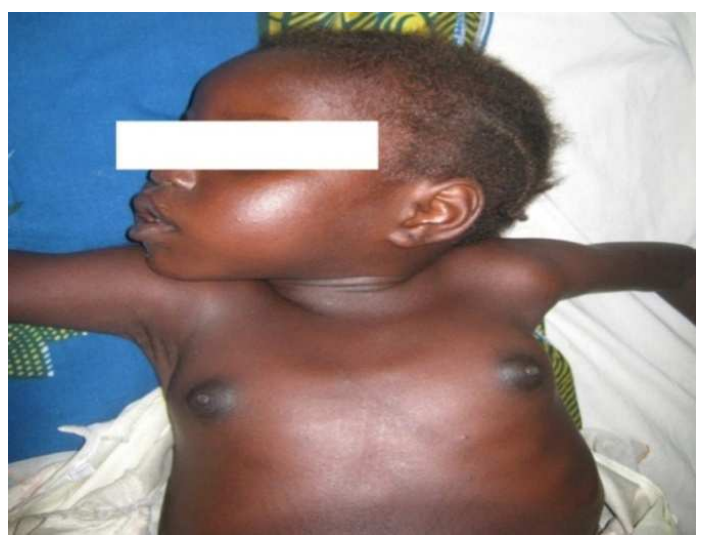

The abdomen was uniformly distended with firm multilobulated masses with cystic areas and well defined upper border. There was no ascitis and her blood pressure was normal. A clinical diagnosis of Wilms' tumour was made with differential diagnoses of abdominal Burkitt lymphoma and abdominal tuberculosis. Investigation results showed a packed cell volume of $26 \%$ with peripheral leucocytosis of $15 \times 10^{9} / \mathrm{L}$ and neutrophilia of $84 \%$. Peripheral blood film showed toxic granulations: ESR was $50 \mathrm{~mm} /$ hour and Mantoux test was negative. Serum electrolytes were within normal limits. Abdominal radiography showed no calcification. Abdominal ultrasound scan showed intraabdominal masses with multiple solid and cystic components but liver, spleen and kidneys were normal. Fine needle aspiration cytology showed features suggestive of a round blue cell tumour of childhood with possibilities of nephroblastoma, neuroblastoma and embryonal rhadomyosarcoma. The patient had exploratory laparatomy which showed huge left tubo-ovarian mass, cystic, multilobulated with well developed arterial supply from the surrounding caecum, transverse colon and the small intestine. The peritoneum was free: there was no ascites and no lymph node enlargement. The liver and spleen were normal.

The patient was offered excisional biopsy of the tumour (left oophrectomy). Histopathological report revealed an encapsulated partly cystic mass measuring 14 X 14 X $9.5 \mathrm{~cm}$. The cut surface showed multilocular cyst containing gelatinous materials as well as solid grey white areas. Microscopically the solid section of the tumour showed some neoplastic cells which were arranged in trabecular, insular, diffuse and microfollicular (CallExner bodies) patterns separated by thin fibrous septae. The nuclei are relatively uniform with abundant cytoplasm. The tumor cells are lacking nuclei grooves (coffee-bean appearance). (Fig 1b) These features are consistent with JGCT. Patient did well postoperatively and regular follow-up for one year showed weight gain, regression of breast enlargement and no evidence of relapse. Patient was not on cytotoxic drugs or any other adjuvant therapy.

Fig 1b: Photomicrograph of Juvenile granulosa cell tumour lacking the "nuclei grooves" (coffee-bean appearance) in a four year old girl. H\&E X180.

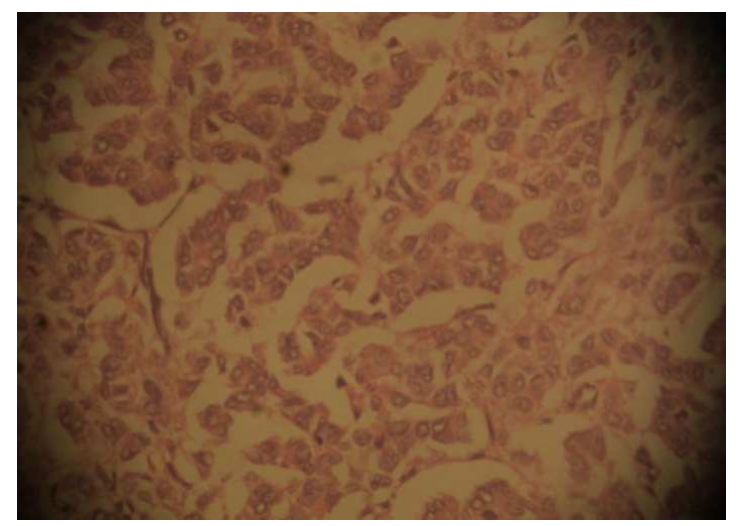

Sections from the ovarian mass show polygonal tumour cells arranged in trabecular, insular and microfollicular (Call-Exner bodies) patterns. The cells nuclei are relatively uniform with abundant cytoplasm. The tumour cells are lacking nuclei grooves (coffee-bean appearance).

\section{Discussion}

Granulosa cell tumours are rare sex cord stroma tumors; incidence varies from $1-5 \%$ of all ovarian tumours. ${ }^{1,2,10}$ A study in Zaria reported $2.1 \%$ prevalence of JGCT in children less than 16 years. ${ }^{3}$ These tumors are divided into JGCT and AGCT: JGCT often occurs within the first three years of life and cases have been reported even in a four months old baby. ${ }^{8,9}$ The index patient presented at the age of four years which falls within the age at which JGCT presents in children. ${ }^{8,9}$ She presented with abdominal swelling, breast enlargement, and abdominal pains these were consistent with various studies reported in the literature. ${ }^{1,10,11}$

Dysfunctional uterine bleeding and menstrual irregularities are frequently seen in women of reproductive age. ${ }^{10}$ Thus it is not surprising that despite breast enlargement and galactorrhoea, the patient herein reported did not present with uterine bleeding. Rare cases of JGCT have been reported to secrete androgen causing virilization. ${ }^{10}$ 
Also, other cases have been associated with Maffuccis syndrome and enchondromatosis (Ollier's disease). ${ }^{11}$ The patient in our report had no evidence of virilization or any other associated condition. Our patient was in stage one disease as the tumor was well capsulated, regional lymph nodes were normal and there was no peritoneal spill. ${ }^{10,11}$ The histological report of this patient was consistent with JGCT, though immunohistochemical staining for inhibin and smooth muscle actin is positive in almost all cases. ${ }^{1,10}$ These tests could not be done in our patient due to lack of reagents which could have given more distinctive findings of JGCT and also helps in monitoring for relapse. Computerized tomographic scan and magnetic resonance imaging could have been useful in diagnosis, but are very expensive.

Some authorities advocate surgical therapy alone for stage one. ${ }^{1,2,4,9}$ In fact others suggest that adjuvant chemotherapy may not be necessary if the tumour can be excised completely. ${ }^{1}$ This is the treatment strategy adopted for our patient since she came in early stage one of the disease. Nevertheless, a variety of chemotherapeutic regimens have been suggested in the literature. ${ }^{3,4}$, $9,10-12$

These include; Cisplatin-based multi drug regimen effective in advanced stage of JGCT, Hormone based treatment with Pacilitaxel and Taxane in combination with Platinum based drugs. Some have used radiotherapy as adjuvant treatment, but other authorities indicated that this does not have any advantage at all. ${ }^{4,10}$

Stage one tumours carry favourable prognosis with fiveyear survival between 95-100\%. Resection of stage onetumour is considered to be curative. Our patient has been followed up for one year now, and so far she is doing well. Relapse in JGCT usually occurs within the first year. ${ }^{10}$ Some advocate follow-up to three years ${ }^{10}$ but recent reports have shown late recurrence of JGCT up to four years later. ${ }^{7}$ These suggest that long term surveillance is highly necessary for this patient. Tumour markers such as inhibin if possible should be used to assess recurrence in addition to other clinical and laboratory investigations for patients.

\section{References}

1. Wang Yi, Wang W, Xu C, Huang $\mathrm{X}$, Zhong L, Kang $\mathrm{X}$ et al. Childhood ovarian juvenile granulosa cell tumour: A retrospective study with three cases including clinical features, pathologic results and therapeutics. J Paediatr Hematol Oncol. 2011; 3: 24 1- 5.

2. PathologyOutline.com. Juvenile granulose cell tumour. www.pathologyOutline.com page 1-4. accessed 18112011.

3. Mohammed A, Malami SA, Calvin B, Abdullahi K. A histopathological study of ovarian neoplasms in children in a tertiary hospital of northern Nigeria. Afr J Paediatr Surg 2010; 7: 75-7

4. Igberase GO, Ebeigbe PN. Huge benign granulose cell tumour in a 61 year old Nigerian grandmultipara with late presentation. Benin J Postgrad Med. 2006; 8:61-6
5. Women's cancer network. State of germ cell and stromal cell cancers overview http://www.wcn.org/ articles/types_of_cancer/ germ_cell/overview. accessed 18 112011.

6. Nicolas K, Ande E, Catherine P, Pierre D, Francoise A, Catherine P et al. Activating mutations of the stimulatory $\mathrm{G}$ protein in juvenile ovarian granulosa cell tumour: A new prognostic factor?. J Clin Endocrinol Metab. 2006; 91 : 1842 - 7.

7. Fransto SD, Geister JP, Fletcher MS, Sood AK. Late recurrence of juvenile granulosa cell tumour of the ovary. Am J Obstet Gynecol 2004; 191: $366-7$.

8. Chad MM. Granulosa- theca cell tumours. In: http:// www.emedicine.medscape.com/ article/254487-overview. Updated Jan 4 2010. accessed 18112011.
9. Schneider DT, Calaminus G, Wesserlowksi R, Pathmanathan R, Selle B et al. Ovarian sex cordstromal tumour in children and adolescence. J Clin Oncol. 2003; 21:2357-63.

10. Kristin RR, William M. An unusual case of juvenile granulosa cell tumour of the ovary. Radiol Case Reports 2009; 4: 178.

11. Young RH, Dickersin GR, Scully RE. Juvenile granulose cell tumour of the ovary: A clinicopathological analysis of 125 cases. Am J Surg Pathol. 1984; 8: 575 - 96.

12. Young RH. Sex cord-stromal tumours of the ovary and testis, their similarities and differences with consideration of selected problems. Modern Pathol. 2005; 18: 581 98 . 